\title{
Sox9 promotes renal tubular epithelial-mesenchymal transition and extracellular matrix aggregation via the PI3K/AKT signaling pathway
}

\author{
ZHIQIANG ZHANG $^{1 *}$, WEI WU ${ }^{1,2 *}$, XIANG FANG ${ }^{1}$, MEI LU $^{1}$, \\ HEYAN WU $^{1}$, CHUNLIN GAO ${ }^{1}$ and ZHENGKUN XIA ${ }^{1}$ \\ ${ }^{1}$ Department of Pediatrics, Jinling Hospital, The First School of Clinical Medicine, \\ Southern Medical University, Nanjing, Jiangsu 210002; ${ }^{2}$ Department of Pediatrics, \\ Longgang District Central Hospital of Shenzhen, Shenzhen, Guangdong 518116, P.R. China
}

Received September 28, 2019; Accepted June 5, 2020

DOI: $10.3892 / \mathrm{mmr} .2020 .11488$

\begin{abstract}
Sox 9 is important for multiple aspects of development, such as testis, pancreas and heart development. Previous studies have reported that Sox9 induced epithelial-mesenchymal transition (EMT) and extracellular matrix (ECM) production in organ fibrosis and associated diseases, such as vascular calcification. However, to the best of our knowledge, the role and underlying mechanism of action of Sox 9 in renal fibrogenesis remains unknown. The results of the present study revealed that Sox9 expression levels were upregulated in the tubular epithelial cells of a rat model of obstructive nephropathy. Furthermore, the overexpression of Sox 9 in NRK-52E cells was discovered to promote renal tubular EMT and ECM aggregation, and these fibrogenic actions were potentiated by TGF- $\beta 1$. Notably, RNA-sequencing analysis indicated the possible regulatory role of the PI3K/AKT signaling pathway in Sox9-mediated renal tubular EMT and ECM aggregation. It was further demonstrated that the expression levels of phosphorylated AKT were upregulated in NRK-52E cells overexpressing Sox9, while the PI3K inhibitors, LY29002 and wortmannin, inhibited the renal tubular EMT and ECM aggregation induced by the overexpression of Sox 9 in NEK-52E cells. In conclusion, the findings of the present study suggested that Sox 9 may serve a profibrotic role in the development of renal tubular EMT and ECM aggregation via the PI3K/AKT
\end{abstract}

Correspondence to: Professor Zhengkun Xia or Professor Chunlin Gao, Department of Pediatrics, Jinling Hospital, The First School of Clinical Medicine, Southern Medical University, 305 Zhongshan East Road, Nanjing, Jiangsu 210002, P.R. China

E-mail:njxzk@126.com

E-mail: shuangmu34@163.com

*Contributed equally

Key words: Sox9, epithelial-mesenchymal transition, extracellular matrix, renal fibrosis, phosphorylated AKT signaling pathway. Therefore, Sox 9 may be considered as a promising target for treating renal fibrosis.

\section{Introduction}

It is currently estimated that there are $>70$ million people with various degrees of chronic kidney disease (CKD) worldwide, affects $8-16 \%$ of the population worldwide (1-5). Renal fibrosis is the final outcome in the majority of CKD cases, despite the different etiologies (6). Renal tubular epithelial-mesenchymal transition (EMT) and the continuous production of extracellular matrix (ECM) proteins have been discovered to be important characteristics of renal fibrosis $(7,8)$. In fact, it has been reported that $5 \%$ of myofibroblasts were derived from tubular EMT in the fibrotic kidney (9). Moreover, renal tubular EMT was identified to promote interstitial fibrosis by secreting inflammatory factor, such as transforming growth factor- $\beta 1$ (TGF- $\beta 1$ ), connective tissue growth factor (CTGF), and ECM proteins (10). In addition, ECM aggregation was demonstrated to lead to widespread tissue fibrosis, promoting the destruction of the renal parenchyma and eventually leading to renal failure (7). Nevertheless, despite the advancements made in recent decades to understand the process of fibrogenesis, the underlying mechanisms remain unknown.

Sox 9 is a member of the highly conserved transcription factor family defined by the similarity of the high mobility group DNA-binding domain of SRY (11). Mutations in and around the Sox 9 gene have been identified in numerous different types of disease, including severe skeletal malformation syndrome, campomelic dysplasia and XY sex reversal in males $(12,13)$. Previous studies have also demonstrated that Sox 9 regulated EMT during embryonic development and the metastasis of epithelial tumors (14-20). During embryonic development, multipotent neural crest cells become migratory, while in EMT, which is induced by Sox 9, these cells were discovered to differentiate into different types of tissue, including the adrenal medulla, cartilage, skin pigment cells and cardiac tissue (14). Moreover, Sox9 has been identified to serve a similar role in the diseased state, particularly in numerous types of tumor; for example, in 
colon (15) and breast cancer cells (16), upregulated expression levels of Sox 9 promoted EMT and cancer cell migration. In addition, previous studies have suggested that Sox 9 may serve a critical role in ECM aggregation (17-20). These observations supported a fundamental role for Sox 9 in the processes of EMT and ECM aggregation.

Transcriptome analysis using RNA-sequencing (RNA-seq) technology has revealed that the expression levels of Sox 9 mRNA were markedly upregulated in the obstructed kidneys of an unilateral ureteral obstruction (UUO) mouse model (21). In addition, the microarray detection of human sclerotic glomeruli captured using laser microscopy discovered that the expression levels of Sox 9 were markedly upregulated, as well as those of collagen $\alpha-1(\mathrm{I})$ chain and collagen $\alpha-2(\mathrm{I})$ chain (22). Furthermore, in mesangial cells, Sox9, as a downstream target of transforming growth factor (TGF)- $\beta 1$, activated collagen $\alpha$-2(IV) chain transcription (23). Based on these previous studies, the present study hypothesized that Sox9 may increase the susceptibility of renal tubular EMT and ECM aggregation.

In order to determine the role and potential mechanism of Sox9 in renal fibrosis, the present study used a UUO rat model and revealed that Sox9 expression levels were significantly upregulated in renal tubular epithelial cells following obstructive injury. In addition, the overexpression of Sox 9 in NRK-52E cells promoted tubular EMT and ECM aggregation, and significantly increased the phosphorylation levels of AKT. Conversely, blocking the PI3K/AKT signaling pathway alleviated the phenotype of fibrosis in NRK-52E cells induced by the overexpression of Sox9. Thus, the present study identified Sox 9 as an important regulator of renal fibrosis.

\section{Materials and methods}

Animal model. All experiments were approved by the Ethics Committee for the Use of Experimental Animals at Jinling Hospital (Nanjing, China). Male Wister rats (age, 5-6 weeks; weight, 180-200 g) were obtained from the Experimental Animal Center of Jinling Hospital. Rats were housed in the animal facility, which was maintained at $20-25^{\circ} \mathrm{C}$ with $55 \%$ relative humidity and an automatic 12 -h light/dark cycle. All rats received a standard laboratory diet and tap water ad libitum. A total of 24 rats was used. To investigate Sox 9 expression levels following obstructive injury, rats were randomly divided into four groups (6/group): i) Sham control; ii) 3 days after UUO; iii) 7 days after UUO; and iv) 14 days after UUO. Rats were anesthetized with an intraperitoneal injection of $5 \%$ chloral hydrate $(400 \mathrm{mg} / \mathrm{kg})$, and vital signs (heart rate, respiratory rate and depth, and body temperature) and reflexes (toe and tail pinch) were monitored to ensure the rats were fully anesthetized. For rats in the UUO groups, the left ureter was exposed using a midline incision and completely ligated $15-\mathrm{mm}$ below the renal pelvis using 4.0 silk. The same procedure was performed in the sham control group, but without ureteral ligation. Rats were sacrificed by cervical dislocation following anesthesia with an intraperitoneal injection of $5 \%$ chloral hydrate $(500 \mathrm{mg} / \mathrm{kg})$ at 3,7 or 14 days following UUO and 14 days following sham operation, and the kidney tissues were harvested and stored at $-80^{\circ} \mathrm{C}$ for subsequent experiments.
Cell culture and treatments. The rat NRK-52E proximal tubular epithelial cell line was purchased from The Cell Bank of Type Culture Collection of the Chinese Academy of Sciences. Cells were cultured in high glucose DMEM (Gibco; Thermo Fisher Scientific, Inc.), supplemented with 8\% FBS (Gibco; Thermo Fisher Scientific, Inc.) and penicillin/streptomycin (penicillin $100 \mathrm{U} / \mathrm{ml}$, streptomycin $0.1 \mathrm{mg} / \mathrm{ml}$; Gibco; Thermo Fisher Scientific, Inc.), and maintained at $37^{\circ} \mathrm{C}$ in $5 \% \mathrm{CO}_{2}$ and $95 \%$ air.

Cells were cultured at $37^{\circ} \mathrm{C}$ in six-well culture plates until $60-70 \%$ confluence, then incubated with serum-free DMEM at $37^{\circ} \mathrm{C}$ for $12 \mathrm{~h}$. Following the incubation, NRK-52E cells were treated at $37^{\circ} \mathrm{C}$ with $10 \mathrm{ng} / \mathrm{ml}$ recombinant TGF- $\beta 1$ (PeproTech, Inc.) or PI3K inhibitors, LY29002 (10 $\mu \mathrm{M}$; Selleck Chemicals) or wortmannin (1 $\mu \mathrm{M}$; Selleck Chemicals), for 24 or $48 \mathrm{~h}$ and subsequently harvested for further analysis.

Lentivirus transduction. The Sox 9 overexpression (LV-Sox9) and negative control (NC; empty vector) lentiviruses were constructed by Shanghai GeneChem Co., Ltd., and lentiviral infections were performed according to the manufacturer's instructions. Briefly, growing cells were seeded into 6-well plates and incubated at $37^{\circ} \mathrm{C}$ for $48 \mathrm{~h}$. Then, $20 \mu \mathrm{l}$ polybrene $\left(5 \mathrm{mg} / \mathrm{ml}\right.$ ) and $50 \mu 1$ virus (storage concentration, $6.0 \times 10^{8} \mathrm{TU} / \mathrm{ml}$ for Sox9 overexpression, $6.2 \times 10^{8} \mathrm{TU} / \mathrm{ml}$ for negative control) was added to $20 \mathrm{ml}$ high glucose DMEM with $8 \%$ FBS and mixed gently. Cells were cultured with the mixture medium $\left(1 \mathrm{ml} /\right.$ well for 6 -well plates) at $37^{\circ} \mathrm{C}$ for $24 \mathrm{~h}$. At $24 \mathrm{~h}$ after infection, the transfection mixture was replaced with high glucose DMEM with 8\% FBS and cultured for a further $48 \mathrm{~h}$ at $37^{\circ} \mathrm{C}$. The transfection efficiency was verified using reverse transcription-quantitative PCR (RT-qPCR) and western blotting in virus-infected cells that were GFP-positive $72 \mathrm{~h}$ following transduction. The infected cells expressing green fluorescent protein (GFP) were observed under a fluorescence microscope (magnification, $\mathrm{x} 400$ magnification). Puromycin $(1 \mu \mathrm{g} / \mathrm{ml}$, Shanghai GeneChem Co., Ltd.) was used to select for stably transfected cell lines.

$R T-q P C R$. Total RNA was extracted from NRK-52E cells and kidney tissue using TRIzol ${ }^{\circledR}$ reagent (Invitrogen; Thermo Fisher Scientific, Inc.), according to the manufacturer's protocol. Total RNA was reverse transcribed into cDNA using a PrimeScript ${ }^{\mathrm{TM}}$ RT Master Mix (cat. no. RR036A; Takara Bio, Inc.), using the following conditions: $37^{\circ} \mathrm{C}$ for $15 \mathrm{~min}$, followed by $85^{\circ} \mathrm{C}$ for $5 \mathrm{sec}$. qPCR was subsequently performed using SYBR ${ }^{\circledR}$ Premix Ex Taq ${ }^{\mathrm{TM}}$ (cat. no. RR420A; Takara Bio, Inc.) according to the manufacturer's protocol, using the following conditions: $94^{\circ} \mathrm{C}$ for $5 \mathrm{~min}$, and followed by 30 cycles of $94^{\circ} \mathrm{C}$ for $30 \mathrm{sec}$ and $58-61^{\circ} \mathrm{C}$ for $3 \mathrm{sec}$. The primer sequences used for the qPCR are presented in Table I. The relative expression levels of the mRNAs were quantified using the $2^{-\Delta \Delta \mathrm{Cq}}$ method (24) and normalized to GAPDH.

Western blotting. Western blotting was performed to analyze the protein expression levels. Briefly, total protein was extracted from kidney tissue or harvested cells using $400 \mu \mathrm{l}$ tissue and cell lysis buffer (RIPA lysis buffer; Beyotime Institute of Biotechnology), supplemented with phosphatase inhibitors and a protease inhibitor (Beyotime Institute of 
Table I. Primers used for reverse transcription-quantitative PCR.

\begin{tabular}{|c|c|}
\hline Gene & Primer sequence $\left(5^{\prime} \rightarrow 3^{\prime}\right)$ \\
\hline \multirow[t]{2}{*}{ GAPDH } & F: TCTCTTGTGACAAAGTGGACAT \\
\hline & R: CCCATTCTCAGCCTTGACTGT \\
\hline \multirow[t]{2}{*}{ Sox9 } & F: AGCACAAGAAAGACCACCCC \\
\hline & R: CGCCTTGAAGATGGCGTTAG \\
\hline \multirow[t]{2}{*}{ E-cadherin } & F: CACCGTGGTTTCTTGCGTTT \\
\hline & R: TCAGGTTCACTGGCATGCTT \\
\hline \multirow[t]{2}{*}{ Vimentin } & F: CAGTCACTCACCTGCGAAGT \\
\hline & R: AGTTAGCAGCTTCAAGGGCA \\
\hline \multirow{4}{*}{$\begin{array}{l}\text { Plasminogen } 1 \\
\text { activator inhibitor } \\
\text { Collagen } 1\end{array}$} & F: CGTCTTCCTCCACAGCCATT \\
\hline & R: GTTGGATTGTGCCGAACCAC \\
\hline & F: ACATGCCGTGACCTCAAGAT \\
\hline & R: ATGTCCATTCCGAATTCCTG \\
\hline \multirow[t]{2}{*}{ Fibronectin } & F: TGGAGAGACAGGAGGAAATAGC \\
\hline & R: CAGTGACAGCATACAGGGTGAT \\
\hline \multirow{4}{*}{$\begin{array}{l}\text { Connective tissue } \\
\text { growth factor } \\
\beta \text {-catenin }\end{array}$} & F: TGGCTTGCTCAGGGTAACTG \\
\hline & R: AACTGCCTCCCAAACCAGTC \\
\hline & F: ATCATTCTGGCCAGTGGTGG \\
\hline & R: GACAGCACCTTCAGCACTCT \\
\hline \multirow[t]{2}{*}{ Frizzled-5 } & F: ACTCGCTACGAGGCTTTGTC \\
\hline & R: CTTAGTGCCACCCTGCTTGA \\
\hline \multirow[t]{2}{*}{ c-Myc } & F: GCTACGTCCTTCTCCCCAAG \\
\hline & R: GGTCTCATCGTCAGGATCGC \\
\hline \multirow{2}{*}{$\begin{array}{l}\text { Transcription } 4 \\
\text { factor }\end{array}$} & F: ATCACAGCAGTGACCCTTGG \\
\hline & R: CCGAGGAGTGCGATGGATAG \\
\hline
\end{tabular}

F, forward; R, reverse.

Biotechnology) on ice. Tissue and cell lysates were centrifuged at $4^{\circ} \mathrm{C}$ for $5 \mathrm{~min}$ at $12,000 \mathrm{x} \mathrm{g}$, total protein was quantified using a bicinchoninic acid protein assay kit (Beyotime Institute of Biotechnology) and $40 \mu \mathrm{g}$ protein/lane was separated via $8 \%$ SDS-PAGE. The separated proteins were subsequently transferred onto PVDF membranes and blocked with 5\% skimmed milk at room temperature for $1 \mathrm{~h}$. The membranes were then incubated overnight at $4{ }^{\circ} \mathrm{C}$ with the following primary antibodies: Anti-Sox9 (1:5,000; cat. no. ab185966; Abcam), anti-E-cadherin (1:1,000; cat. no. ab76055; Abcam), anti-Vimentin (1:5,000; cat. no. ab92547; Abcam), anti-plasminogen activator inhibitor 1 (PAI-1; 1:2,000; cat. no. ab66705; Abcam), anti-collagen 1 (COL1; 1:1,000; cat. no. AF7001; Affinity Biosciences), anti-fibronectin (1:5,000; cat. no. ab45688; Abcam), anti- $\beta$-catenin (1:5,000; cat. no. ab32572; Abcam), anti-AKT (1:2,000; cat. no. AF6261; Affinity Biosciences), anti-phosphorylated (p)-AKT (1:5,000; cat. no. ab81283; Abcam) and anti- $\beta$-actin $(1: 10,000$; cat. no. bsm-33036M; BIOSS). Following the primary antibody incubation, the membranes were incubated with either an anti-mouse IgM horseradish peroxidase (HRP)-conjugated secondary antibody (1:5,000; cat. no. bs-0368R-HRP; BIOSS) or an anti-rabbit IgG HRP-conjugated secondary antibody (1:5,000; cat. no. bs-0295G-HRP; BIOSS) at room temperature for $2 \mathrm{~h}$. Protein bands were visualized using an enhanced chemiluminescence reagent (Beyotime Institute of Biotechnology) and the FluorChem M system (ProteinSimple). ImageJ software (version 1.5.1; National Institutes of Health) was used to perform densitometric analysis. The expression levels were analyzed and normalized to $\beta$-actin, the internal loading control.

Histology and immunohistochemistry. The fresh kidney tissue was fixed in $4 \%$ paraformaldehyde at $4^{\circ} \mathrm{C}$ overnight, subsequently embedded in paraffin and sliced into sections (thickness, $5 \mu \mathrm{m}$ ). For histological analysis, the kidney sections were deparaffinized and rehydrated in a descending ethanol series (100 and $75 \%$ ethanol at room temperature for $5 \mathrm{~min}$ ). The sections were subsequently stained with Masson's trichrome stain kit (cat. no. BSBA-4079A; OriGene Technologies, Inc.). Briefly, the sections were stained with hematoxylin iron solution for $3 \mathrm{~min}$ at room temperature, followed by $0.5 \%$ acid alcohol, and washed in water once more. Samples were stained with Ponceau S solution for $5 \mathrm{~min}$ at room temperature, and subsequently rinsed in water. Finally, samples were stained using phosphomolybdic acid for $1 \mathrm{~min}$ at room temperature, followed by aniline blue solution for $3 \mathrm{~min}$ at room temperature, and washed with $1 \%$ acetic acid solution at room temperature. Masson staining evaluated kidney histological changes, such as the fibrotic area, indicated by blue staining, and the degree of tubular atrophy. The samples were examined by light microscopy (magnification, x200).

Immunohistochemistry was performed using the paraffin-embedded kidney samples. The paraffin sections were subsequently de-waxed in water, and incubated with $3 \%$ hydrogen peroxide at room temperature for $10 \mathrm{~min}$. Subsequently, the sections were blocked with 5\% goat serum (cat. no. 16210064; Thermo Fisher Scientific, Inc.) in PBS at room temperature for $1 \mathrm{~h}$ and then incubated overnight at $4^{\circ} \mathrm{C}$ with the anti-Sox 9 primary antibody $(1: 2,000)$. Following the primary antibody incubation, the sections were incubated with an HRP-conjugated goat anti-rabbit secondary antibody (1:5,000; cat. no. bs-40295G-HRP; BIOSS) at room temperature for $2 \mathrm{~h}$. The slides were visualized using 3,3'-diaminobenzidine (Beyotime Institute of Biotechnology) and counterstained with hematoxylin at room temperature for $2 \mathrm{~min}$. The samples were examined by light microscopy (magnification, $\mathrm{x} 400$ ).

Immunofluorescence staining. Cells at $80 \%$ confluence were cultured on coverslips were fixed with $4 \%$ paraformaldehyde at room temperature for $15 \mathrm{~min}$ and blocked with $5 \%$ goat serum (Gibco; Thermo Fisher Scientific, Inc.) in PBS at room temperature for $30 \mathrm{~min}$. The coverslips were then incubated overnight at $4{ }^{\circ} \mathrm{C}$ with the following primary antibodies: Anti-COL1 (1:1,500) and anti-fibronectin (1:500). Following the primary antibody incubation, the coverslips were washed 3 times with PBS and incubated with a goat anti-rabbit IgG antibody labeled with Alexa Fluor ${ }^{\circledR} 546(4 \mu \mathrm{g} / \mathrm{ml}$; cat. no. A-11035; Invitrogen; Thermo Fisher Scientific, Inc.) for $1 \mathrm{~h}$ at room temperature in the dark. The nuclei were counterstained with DAPI (Thermo Fisher Scientific, Inc.) at room temperature for $5 \mathrm{~min}$. Stained slides were visualized using a 
fluorescence microscope (magnification, x400) (Imager A2; Zeiss $\mathrm{GmbH})$.

RNA-seq and bioinformatics analysis. Total RNA was extracted using TRIzol ${ }^{\circledR}$ reagent (Invitrogen; Thermo Fisher Scientific, Inc.) from SV-Sox9- or NC-transfected NRK-52E cells and sequenced by CapitalBio Technology Inc.. The mRNA profiling was performed using the Illumina HiSeq 2500 platform (Illumina, Inc.). The lists of differentially expressed genes were analyzed via Cuffdiff software (version 2; cufflinks.cbcb.umd.edu) (25). The differentially expressed genes (Ifold-changel $>2$ and $\mathrm{P}<0.05$ ) were subjected to functional term and signaling pathway enrichment analysis using Gene Ontology (GO; geneontology.org) (26) and Kyoto Encyclopedia of Genes and Genomes (KEGG) (27) databases, respectively.

Statistical analysis. Statistical analysis was performed using SPSS 20 software (IBM Corp.) and data are presented as the mean \pm SD of $\geq 3$ independent experiments. A Student's t-test or a one-way ANOVA, followed by a Tukey's post-hoc test was used to determine the statistical significances between 2 and $>2$ groups, respectively. $\mathrm{P}<0.05$ was considered to indicate a statistically significant difference.

\section{Results}

Expression levels of Sox9 are upregulated in the tubules of UUO model rats. The obstructive nephropathy induced after UUO is a classic model of renal interstitial fibrosis, characterized by tubular EMT and high levels of ECM aggregation (28). The expression levels of E-cadherin were downregulated and those of Vimentin, COL1 and fibronectin were upregulated in a time-dependent manner in UUO model rats, which indicated that the model of renal fibrosis had been successfully established (Fig. 1A and B).

To determine whether the expression levels of Sox 9 in renal fibrosis were altered, the expression levels of Sox9 in the UUO model rats were analyzed. The experimental data revealed that the mRNA expression levels of Sox 9 were upregulated by $>2-$, 4- and 5-fold at 3, 7 and 14 days following UUO, respectively, compared with the sham group (Fig. 1C). In addition, western blotting demonstrated that the protein expression levels of Sox 9 were upregulated in the obstructed kidneys at 7 and 14 days following UUO compared with the sham group (Fig. 1D).

To further determine the type of cell in which Sox 9 protein expression levels were upregulated, Sox 9 protein expression levels were investigated using immunohistochemical staining in the fibrotic kidneys of the UUO model rats. Sox 9 protein expression levels were markedly upregulated in the obstructed kidneys by 7 and 14 days following UUO compared with the sham group (Fig. 1E), which were positively associated with the severity of kidney fibrosis stained with Masson's staining Notably, Sox 9 protein expression levels were identified to be markedly upregulated in renal tubular epithelial cells (black arrows; Fig. 1E).

Overexpression of Sox9 in tubular epithelial cells induces renal tubular EMT and ECM aggregation. As Sox9 protein was identified to be abundantly expressed in renal tubular epithelial cells following obstructive injury, NRK-52E cells were transfected with LV-Sox9 to investigate the role of Sox 9; the transfection efficiency was revealed to be $90 \%$ in NRK-52E cells infected with the lentivirus for $72 \mathrm{~h}$ following the observation with a fluorescence microscope (Fig. 2A). The transfection efficiency was also analyzed using RT-qPCR and western blotting; the mRNA and protein expression levels of Sox 9 were significantly upregulated in LV-Sox9-transfected cells compared with the NC-transfected cells (Fig. 2B and C).

The overexpression of Sox 9 significantly upregulated the mRNA expression levels of Vimentin, PAI-1, COL1, fibronectin and connective tissue growth factor (CTGF) compared with the NC-transfected cells, which is consistent with EMT and ECM production (7-9) (Fig. 2D). In addition, compared with the NC-transfected cells, the LV-Sox9-transfected cells demonstrated upregulated protein expression levels of Vimentin, PAI-1, COL1 and fibronectin in the tubular epithelial cells (Fig. 2E and F). However, there was no effect on the expression levels of E-cadherin compared with NC-transfected cells.

Sox9 aggravates tubular EMT and ECM aggregation induced by TGF- $\beta 1$ in tubular epithelial cells. To determine whether the overexpression of Sox 9 aggravated the renal tubular EMT and ECM aggregation induced by TGF- $\beta 1$, LV-Sox9-transfected NRK-52E cells were treated with TGF- $\beta 1$. RT-qPCR analysis revealed that the overexpression of Sox 9 potentiated the TGF- $\beta 1$-induced downregulation of E-cadherin expression levels, and upregulation of Vimentin, PAI-1, COL1, fibronectin and CTGF expression levels (Fig. 3A). Similarly, western blotting revealed that the overexpression of Sox 9 enhanced the TGF- $\beta 1$-induced downregulation of E-cadherin protein expression levels and upregulation of Vimentin, PAI-1, COL1 and fibronectin protein expression levels (Fig. 3B and C). Compared with the NRK-52E cells without TGF- $\beta 1$ treatment, the cells treated with TGF- $\beta 1$ had upregulated expression levels of Vimentin, PAI-1, COL1 and fibronectin and downregulated E-cadherin expression levels. Immunofluorescence staining to determine COL1 and fibronectin expression levels following the treatment with TGF- $\beta 1$ revealed similar results to the RT-qPCR and western blotting data (Fig. 3C). Therefore, these findings suggested that the overexpression of Sox 9 may potentiate renal tubular EMT and ECM aggregation induced by TGF- $\beta 1$ in tubular epithelial cells.

PI3K/AKT signaling pathway is activated following Sox9 overexpression in tubular epithelial cells. An increasing number of studies have revealed that Sox 9 acts primarily through the Wnt/ $\beta$-catenin signaling pathway (29-32). Therefore, to identify molecular responders of Sox9, it was investigated whether Sox9 could activate Wnt signaling molecules in NRK-52E cells. The results revealed that no statistical differences were observed in the mRNA and protein expression levels of $\beta$-catenin, a crucial mediator of canonical Wnt signaling, between NC- and LV-Sox9-transfected cells (Fig. S1A and S1B). In addition, the overexpression of Sox 9 did not affect the mRNA expression levels of Wnt receptors, such as Frizzled-5 (FZD5), or their target genes, including c-Myc and transcription factor 4 (TCF4; Fig. S1C). 
A
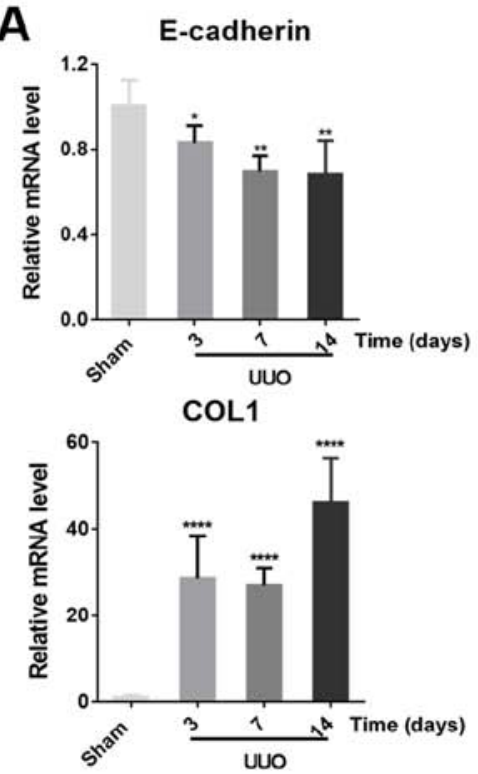

C

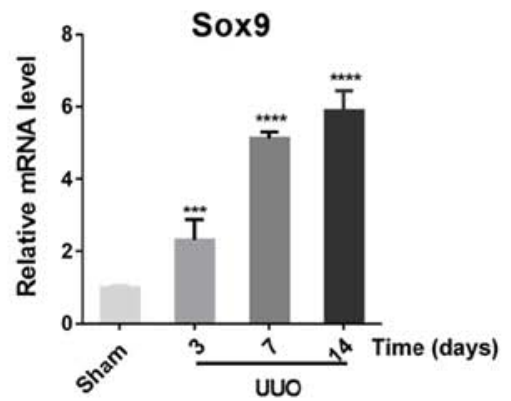

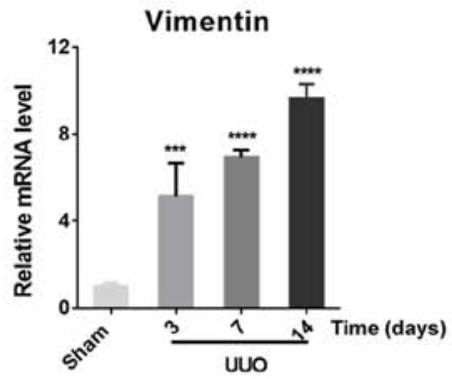

Fibronectin

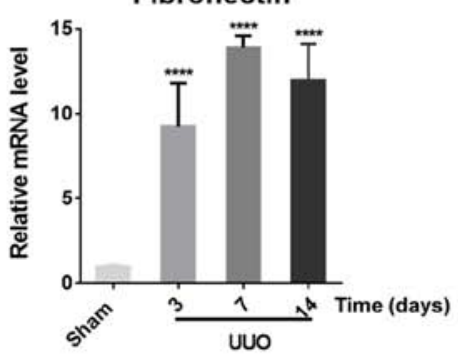

B

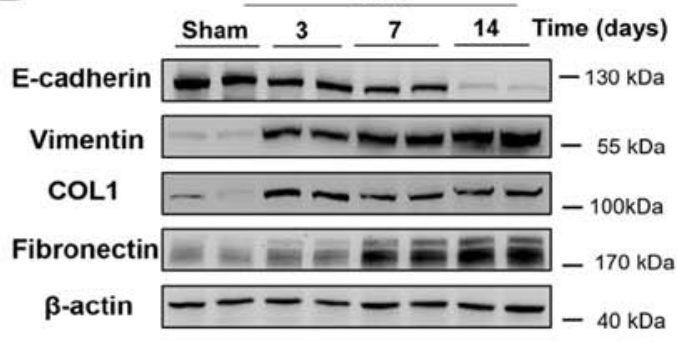

D

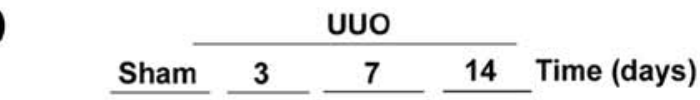

Sox9 $--10 \mathrm{kDa}$

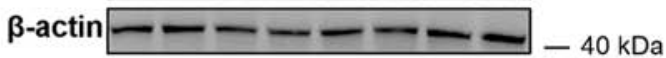

E
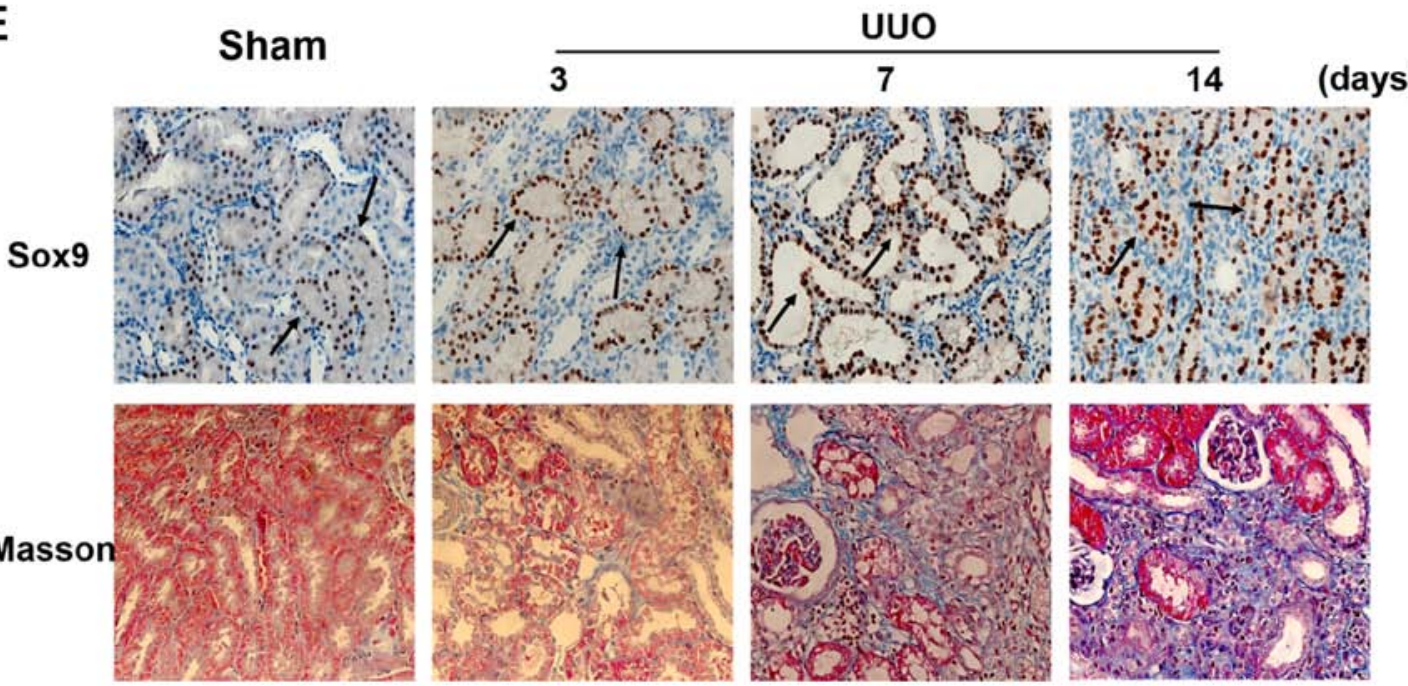

Figure 1. Expression levels of EMT and fibrotic markers and Sox9 in UUO-induced kidney fibrosis. (A) mRNA and (B) protein expression levels of E-cadherin, Vimentin, fibronectin and COL1 in the sham control and the obstructed kidneys following UUO for 3, 7 or 14 days. (C) mRNA and (D) protein expression levels of Sox9 in the obstructed kidneys in the sham control and the obstructed kidneys following UUO for 3, 7 or 14 days. $n=6$ rats/group, western blotting experiments were repeated once. (E) Immunohistochemical staining revealed the expression levels and localization of Sox9 protein in the sham control and the obstructed kidneys following UUO for 3, 7 or 14 days. Masson's trichrome staining was used to identify areas of fibrosis (blue staining) in the sham control and the obstructed kidneys following UUO for 3, 7 or 14 days. Arrows indicate positive staining of Sox9. Magnification, $x 400$ for immunohistochemical staining, x200 for Masson's trichrome staining. Data are presented as the mean $\pm \mathrm{SD}$. ${ }^{*} \mathrm{P}<0.05,{ }^{* * *} \mathrm{P}<0.01,{ }^{* * * *} \mathrm{P}<0.001,{ }^{* * * * * *} \mathrm{P}<0.0001$ vs. sham. UUO, unilateral ureteral obstruction; COL1, collagen 1.

To further determine how Sox 9 may regulate renal tubular EMT and ECM aggregation, mRNA transcriptome analysis using RNA-seq technology was performed in NRK-52E cells overexpressing Sox9. A total of 317 differentially expressed genes were identified (Ifold-changel $>2$ and $\mathrm{P}<0.05$ ), including 174 upregulated and 143 downregulated genes 
A

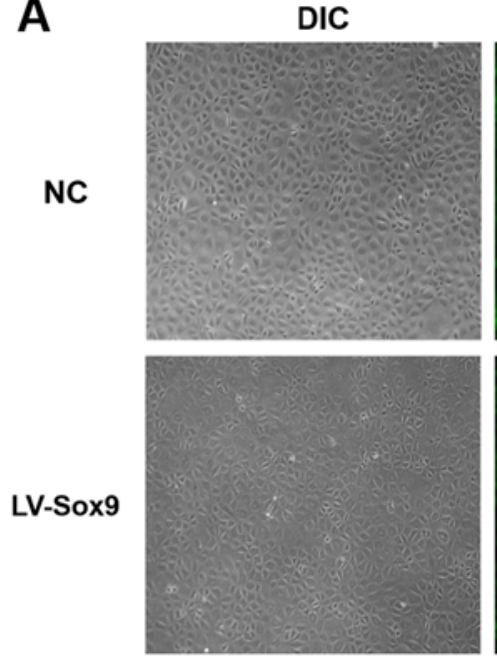

D

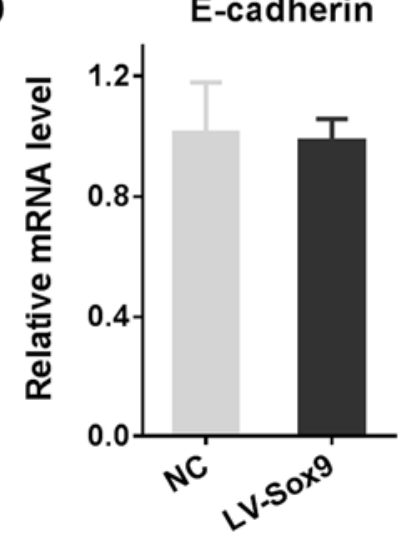

COL1

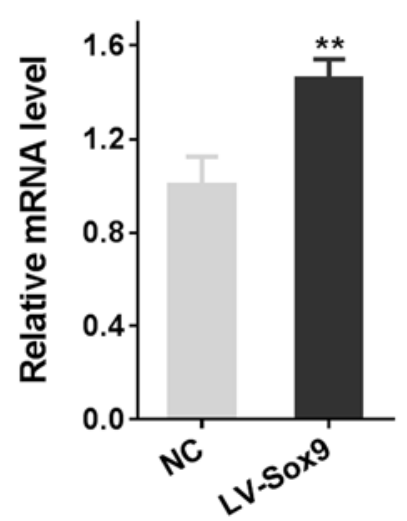

GFP
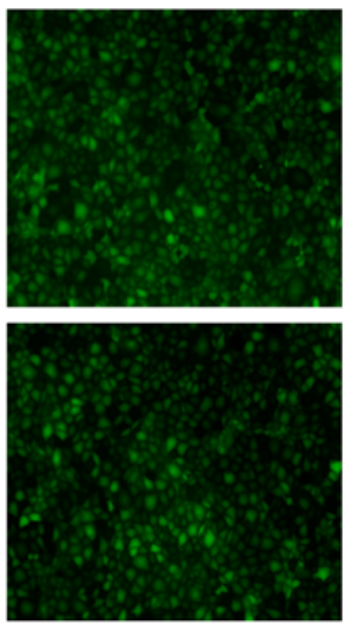

B
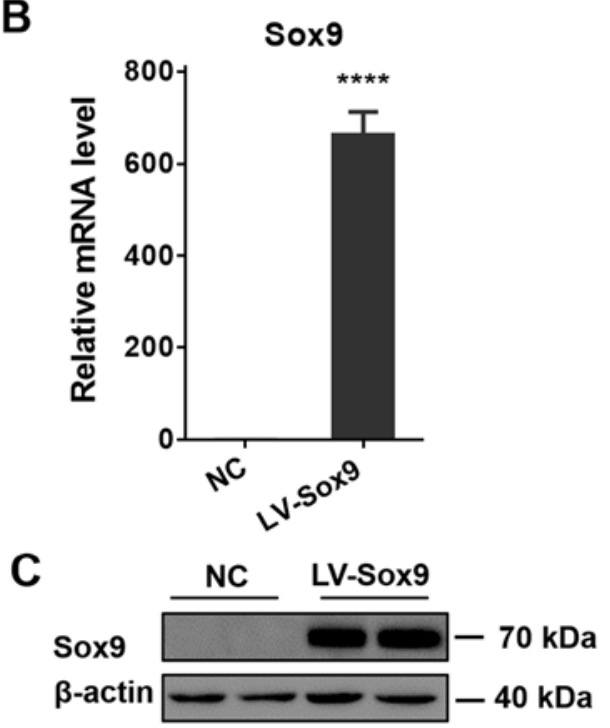

Vimentin

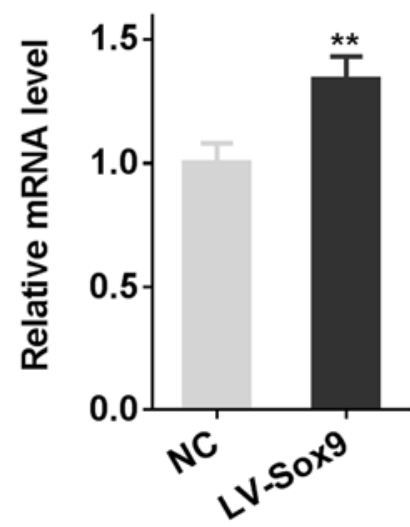

Fibronectin

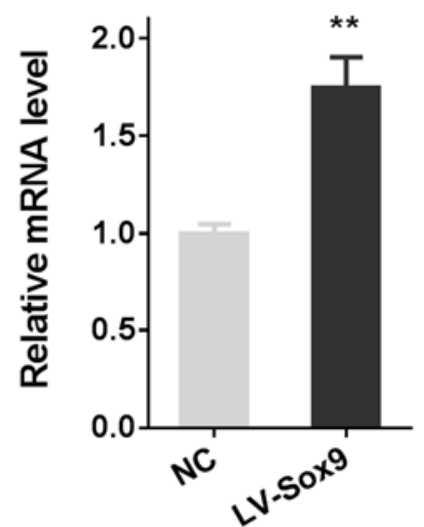

PAI-1

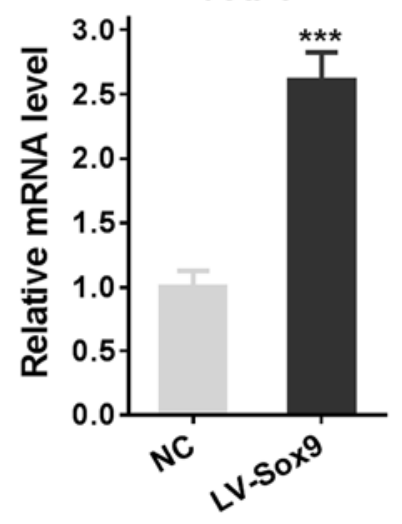

CTGF

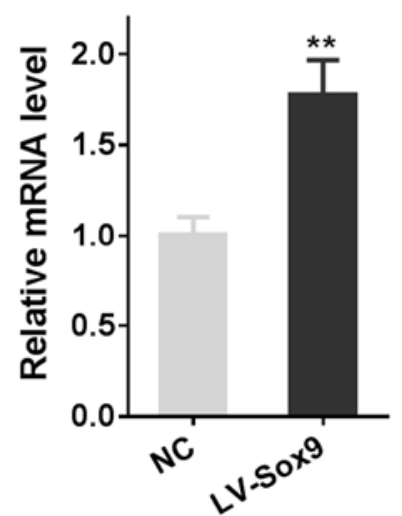

Figure 2. Overexpression of Sox9 in tubular epithelial cells induces renal tubular epithelial-mesenchymal transition and extracellular matrix aggregation. NRK-52E cells were transfected with LV-Sox9 or NC. (A) Transfection efficiency was observed under a fluorescence microscope. Magnification, x400. The transfection efficiency of LV-Sox9 was also analyzed using (B) RT-qPCR and (C) western blotting. (D) RT-qPCR was used to analyze the expression levels of E-cadherin, Vimentin, PAI-1, COL1, fibronectin and CTGF in tubular epithelial cells following the overexpression of Sox9. n=3/group.

(Fig. 4A). Subsequently, GO functional term and KEGG signaling pathway enrichment analysis were performed to identify the potential physiological functions of the differentially expressed mRNAs. GO analysis discovered that the differentially expressed genes were highly associated with 'Extracellular space', 'Extracellular region part', 'Extracellular region' and 'Contractile fiber part' (Fig. 4B). KEGG analysis also identified that the differentially expressed genes was involved in the 'PI3K-Akt signaling pathway' and the 'HIF-1 signaling pathway' (Fig. 4C). Previous studies have reported that in chondrocytes and human lung fibroblast cell line, the knockdown of Sox 9 downregulated the phosphorylation levels 


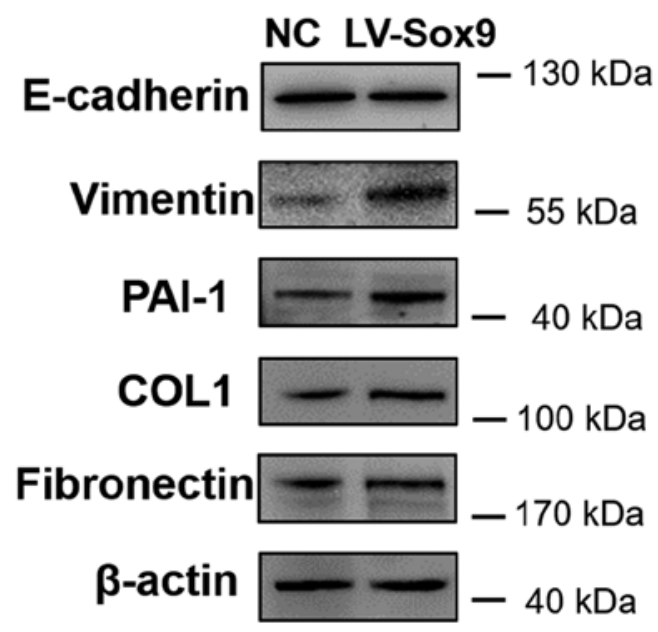

\section{$\mathbf{F}$}

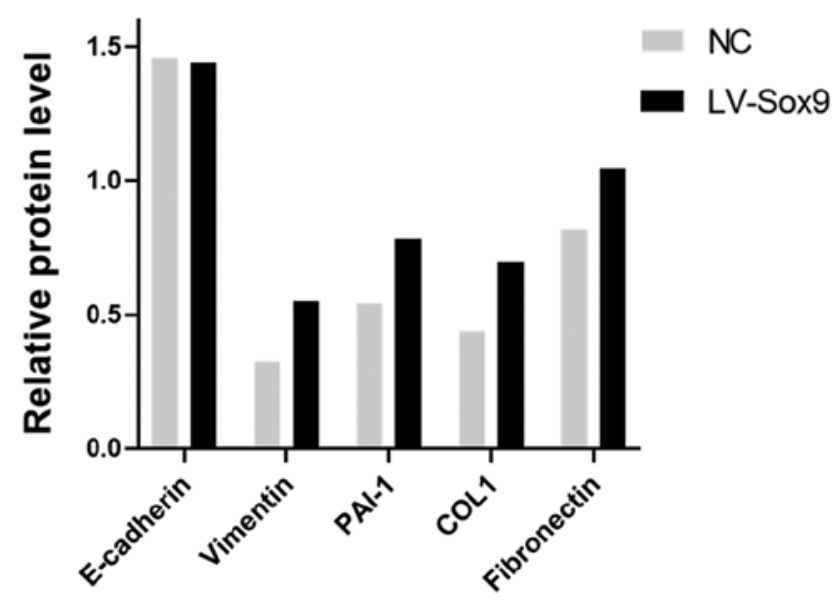

Figure 2. Continued. Overexpression of Sox9 in tubular epithelial cells induces renal tubular epithelial-mesenchymal transition and extracellular matrix aggregation. NRK-52E cells were transfected with LV-Sox9 or NC. (E) Western blotting was used to analyze the expression levels of E-cadherin, Vimentin, PAI-1, COL1 and fibronectin in tubular epithelial cells following the overexpression of Sox9. n=3/group, western blotting experiments were repeated once. (F) Semi-quantification of the expression levels presented in part (E). Data are presented as the mean $\pm \mathrm{SD} .{ }^{* * *} \mathrm{P}<0.01,{ }^{* * * *} \mathrm{P}<0.001,{ }^{* * * * *} \mathrm{P}<0.0001$ vs. NC. LV-Sox9, stabilized Sox9 expressing lentivirus; NC, negative control; DIC, differential interference contrast microscope; PAI-1, plasminogen activator inhibitor 1; COL1, collagen 1; CTGF, connective tissue growth factor; RT-qPCR, reverse transcription-quantitative PCR.

of AKT $(33,34)$. Therefore, it was investigated whether Sox9 regulated AKT activity in NRK-52E cells. The overexpression of Sox 9 did not upregulate the protein expression levels of total AKT in NRK-52E cells; however, the protein expression levels of p-AKT were upregulated in LV-Sox9-transfected cells compared with NC-transfected cells (Fig. 4D).

Blockade of PI3K/AKT signaling pathway with PI3K inhibitors alleviates the tubular EMT and ECM aggregation caused by the overexpression of Sox 9 in tubular epithelial cells. The inhibitors of PI3K, LY29002 and wortmannin, were used to investigate whether the Sox9-induced renal tubular EMT and ECM aggregation was caused by activation of the PI3K/AKT signaling pathway. The protein and/or mRNA expression levels of Vimentin, PAI-1, COL1 and fibronectin were significantly downregulated in cells overexpressing Sox9 following the treatment with LY294002 or wortmannin compared with the LV-Sox9-transfected cells alone (Fig. 5A-C). In addition, the treatment of LV-Sox9-transfected cells with wortmannin or LY29002 downregulated the protein expression levels of p-AKT compared with LV-Sox9-transfected cells (Fig. 5B and C). These results suggested that the overexpression of Sox9 may induce tubular epithelial EMT and ECM aggregation, at least in part, through activation of the PI3K/AKT signaling pathway.

\section{Discussion}

Numerous studies have demonstrated that Sox9 is as an important transcription factor involved in organ development, including the development of the kidney $(35,36)$. Sox 9 activation has also been associated with chronic fibrotic disorders in the liver $(17,20)$ and the heart $(18)$. However, to the best of our knowledge, the role of Sox9 in renal interstitial fibrosis remains poorly understood. The present study revealed that the expression levels of Sox 9 were upregulated in renal tubular epithelial cells following obstructive injury, and that the overexpression of Sox 9 in NRK-52E cells promoted tubular EMT and ECM aggregation. Furthermore, the overexpression of Sox9 upregulated the phosphorylation levels of AKT, while the PI3K inhibitors, LY29002 and wortmannin, attenuated the phenotype of fibrosis in NRK-52E cells induced by the 
A
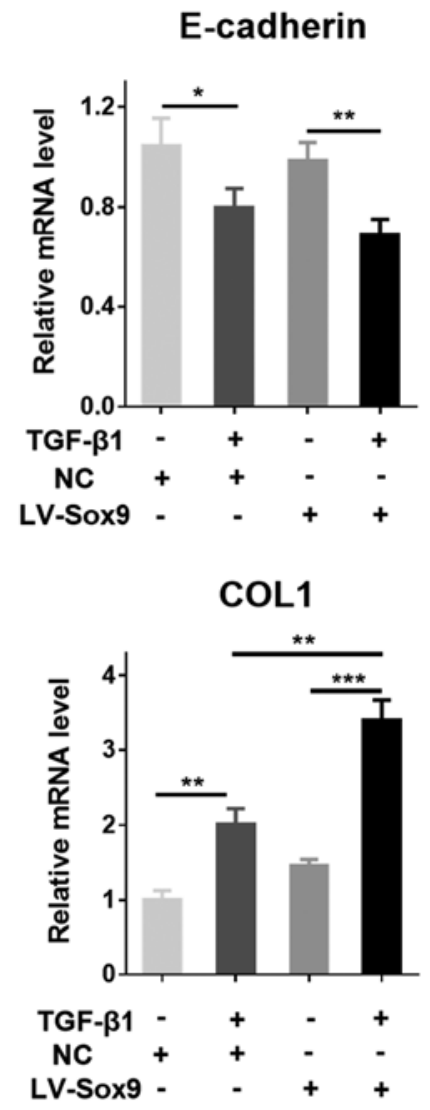

Vimentin

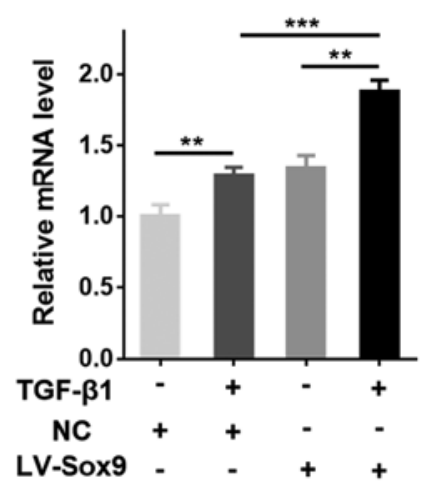

Fibronectin

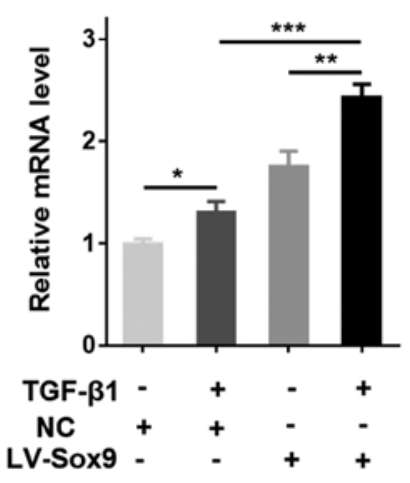

PAl-1

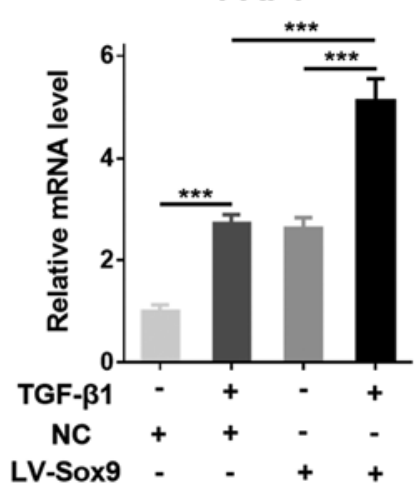

CTGF

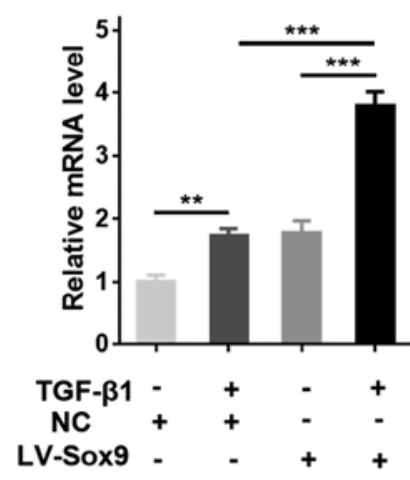

B

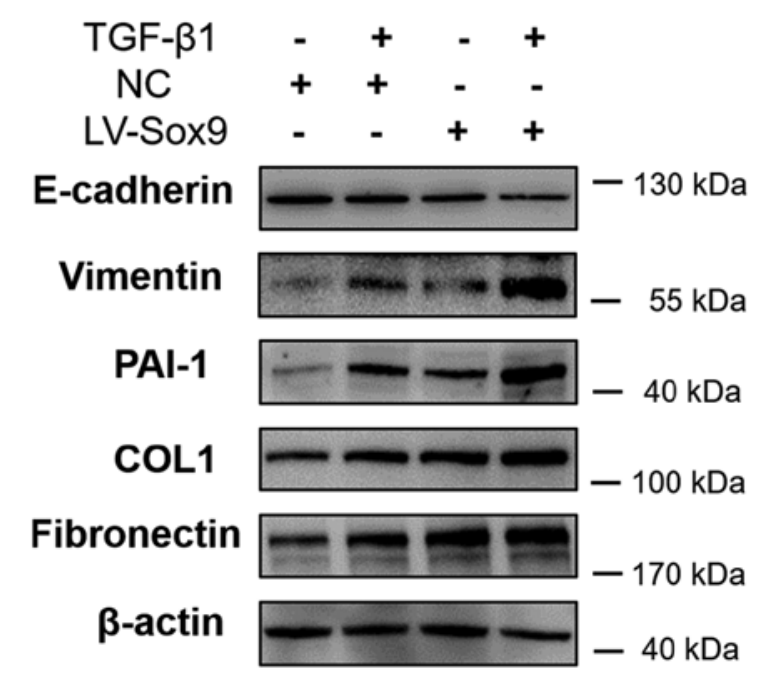

Figure 3. Sox 9 potentiates the tubular epithelial-mesenchymal transition and extracellular matrix aggregation induced by TGF- $\beta 1$ in tubular epithelial cells. NRK-52E cells were transfected with LV-Sox 9 or NC and then treated with TGF- $\beta 1(10 \mathrm{ng} / \mathrm{ml})$ for various periods of time as indicated. (A) Reverse transcription-quantitative PCR was used to analyze the expression levels of E-cadherin, Vimentin, PAI-1, COL1, fibronectin and CTGF in LV-Sox9- or NC-transfected NRK-52E cells treated with TGF- $\beta 1$ for 24 h. (B) Western blotting was used to analyze the expression levels of E-cadherin, Vimentin, PAI-1, COL1 and fibronectin in LV-Sox9- or NC-transfected NRK-52E cells treated with TGF- $\beta 1$ for $48 \mathrm{~h}$. $\mathrm{n}=3$ /group, western blotting experiments were repeated once.

overexpression of Sox9. Thus, these findings indicated that Sox9 may be an important regulator of renal tubular EMT and ECM aggregation, suggesting its potential as a novel target for therapeutic interference in CKD.

Firstly, a UUO model of renal fibrosis was established and confirmed via detecting EMT and fibrotic markers and Masson's staining. The expression levels of E-cadherin protein were notably downregulated at 14 days following UUO, whereas the
mRNA expression levels remained stable. This was consistent with a previous study by Geng et al (37), which reported that numerous post-translational modifications may regulate the protein expression levels of E-cadherin in human breast cancer cells. Secondly, the role of Sox9 in the development of renal fibrosis during obstructive injury was investigated. The mRNA and protein expression levels of Sox 9 were significantly upregulated in a time-dependent manner in the kidney tissue and in 
C

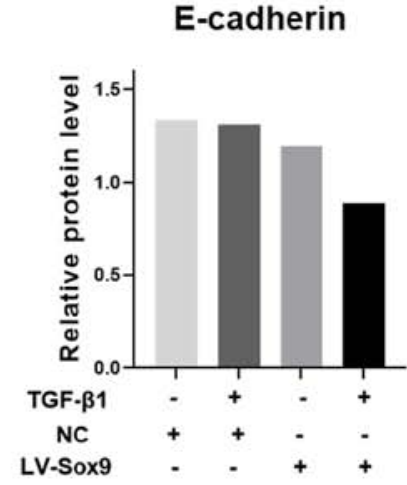

COL1

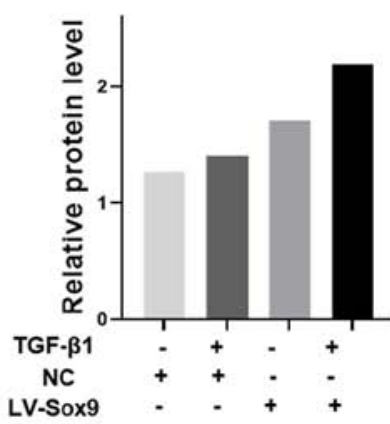

D

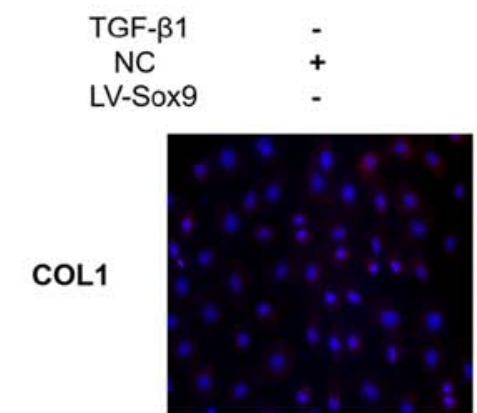

Fibronectin
Vimentin

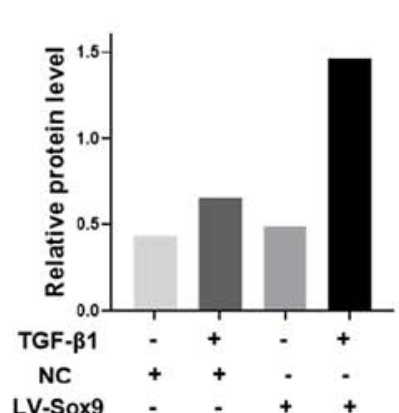

Fibronectin

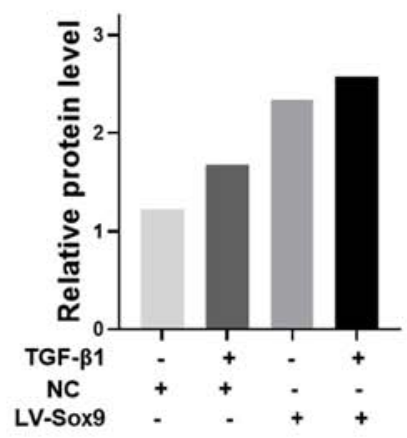

PAl-1

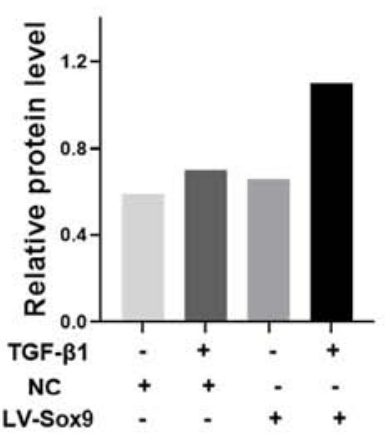

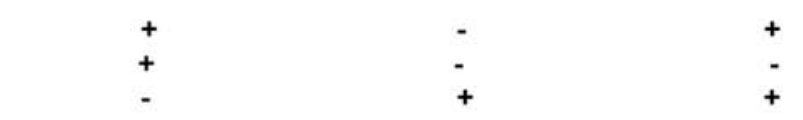
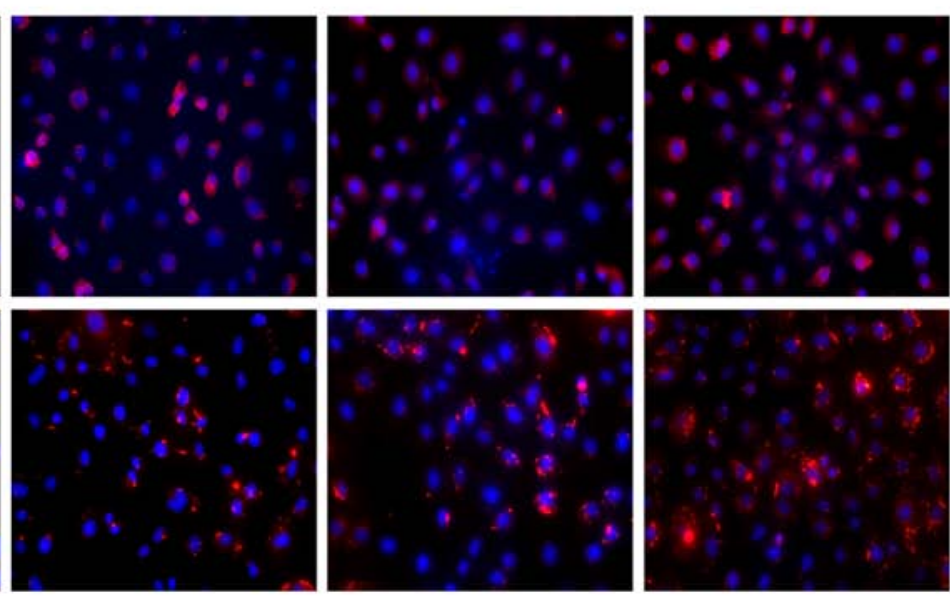

Figure 3. Continued. Sox 9 potentiates the tubular epithelial-mesenchymal transition and extracellular matrix aggregation induced by TGF- $\beta 1$ in tubular epithelial cells. NRK-52E cells were transfected with LV-Sox 9 or NC and then treated with TGF- $\beta 1$ (10 ng/ml) for various periods of time as indicated. (C) Semi-quantification of the expression levels presented in part (B). (D) Immunofluorescence staining was used to analyze the protein expression levels of COL1 and fibronectin in the LV-Sox9- or NC-transfected NRK-52E cells treated with TGF- $\beta 1$ for 48 h. Magnification, x400. Data are presented as the mean \pm SD. ${ }^{*} \mathrm{P}<0.05,{ }^{* *} \mathrm{P}<0.01,{ }^{* * *} \mathrm{P}<0.001$. LV-Sox9, stabilized Sox9 expressing lentivirus; NC, negative control; PAI-1, plasminogen activator inhibitor 1; COL1, collagen 1; CTGF, connective tissue growth factor; TGF- $\beta 1$, transforming growth factor $\beta 1$.

tubular epithelial cells following renal fibrosis. These data suggested a possible association between Sox 9 and renal fibrosis, and are consistent with a previous study by Kumar et al (38), which reported that the expression levels of Sox 9 were upregulated in renal tubular epithelial cells in an acute kidney injury (AKI) model. In addition, the activation of Sox 9 was involved in the repair process of renal tubular epithelial cells following AKI (38). These findings demonstrated the potential role of Sox9 in the repair process of renal tubular epithelial cells following AKI; however, the role and underlying mechanism of action of Sox 9 in renal fibrogenesis remains unknown. An additional study comparing RNA-seq analysis at various time points during the process from AKI to chronic kidney injury revealed that the expression levels of Sox 9 were maintained, even weeks after AKI, indicating that Sox9 may not only be involved in the repair process, but also in the process of chronic fibrosis (39). 
A

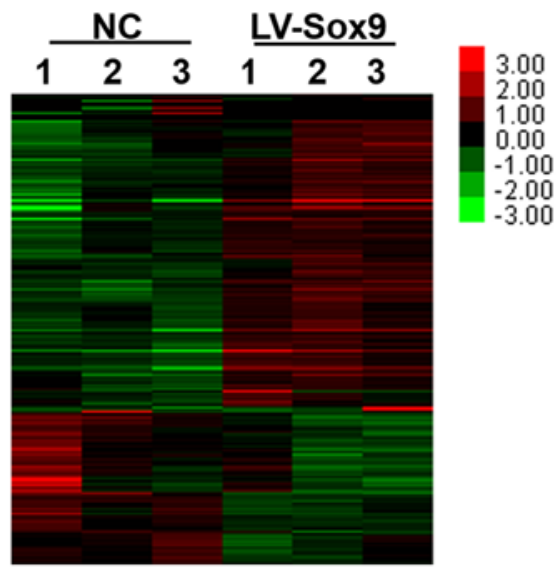

B

Significantly enriched GO signaling pathway terms (top 10)

$$
\text { Extracellular space }
$$

Extracellular region part

Extracellular region

Contractile fiber part

I band

Cytoplasmic membrane-bounded vesicle

Contractile fiber

Transport vesicle

Cytoplasmic vesicle

Sarcomere

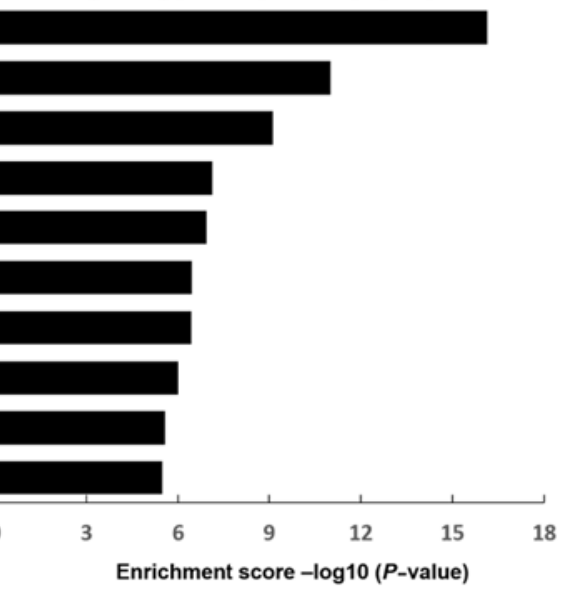

Significantly enriched KEGG signaling pathway terms (top 10)

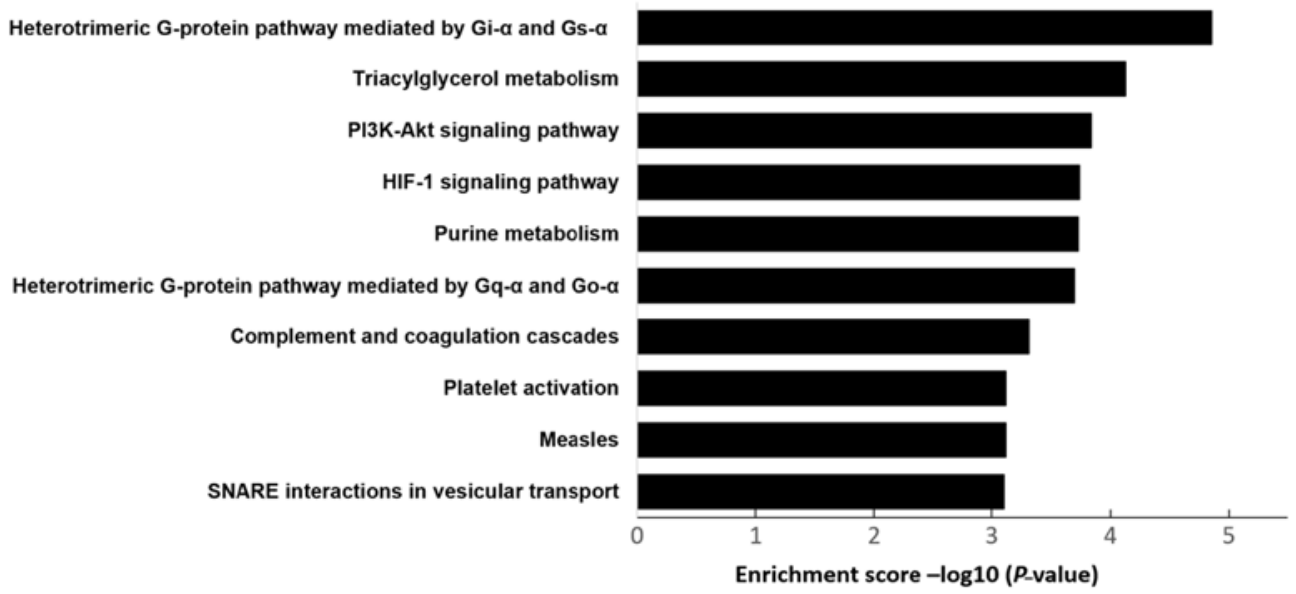

D

E

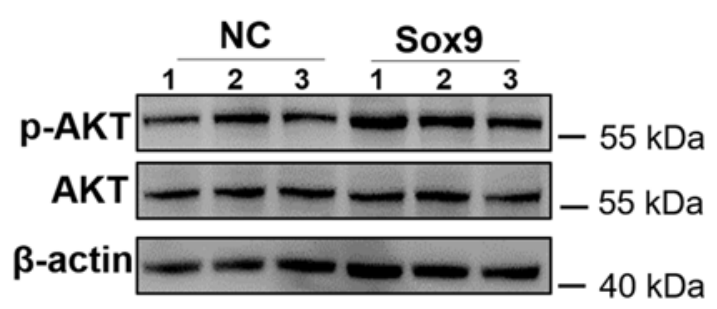

p-AKT/ AKT

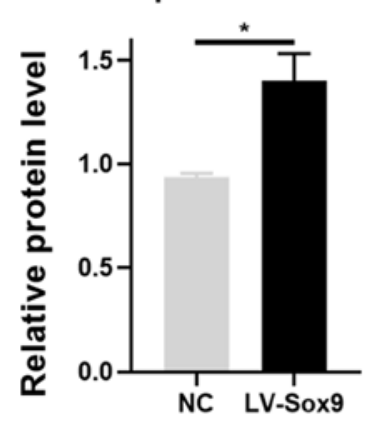

Figure 4. PI3K/AKT signaling pathway is activated following Sox 9 overexpression in tubular epithelial cells. (A) Clustering analysis by Illumina HiSeq 2500 demonstrated changes in the mRNA expression profiles in LV-Sox9-transfected NRK-52E cells. n=3/group. (B) Significantly enriched GO terms among differentially expressed genes in LV-Sox9-transfected cells relative to NC-transfected cells. (C) Significantly enriched KEGG signaling pathway terms among differentially expressed genes in LV-Sox9-transfected cells relative to NC-transfected cells. (D) Western blotting analysis of p-AKT and AKT expression levels in NRK-52E cells transfected with LV-Sox9. (E) Semi-quantification of the expression levels presented in part (D). n=3/group, western blotting experiments were repeated once. "P<0.05. LV-Sox9, stabilized Sox9 expressing lentivirus; NC, negative control; GO, Gene Ontology; p-, phosphorylated; KEGG, Kyoto Encyclopedia of Genes and Genomes.

Renal tubular epithelial cells are the primary target of a variety of metabolic, immunological, ischemic and toxic insults $(40,41)$. In the tubulointerstitium, renal tubular epithelial cells were also discovered to serve a significant role in promoting the release of inflammatory factors and ECM aggregation through epithelial-mesenchymal communication (42).
In the present study, Sox9 expression levels were upregulated in the renal tubular epithelium in obstructive nephropathy; thus, indicating a potential important role of Sox 9 in promoting renal tubular EMT and ECM aggregation following the overexpression of Sox 9 in NRK-52E cells. Furthermore, the overexpression of Sox9 in tubular epithelial cells upregulated 
A

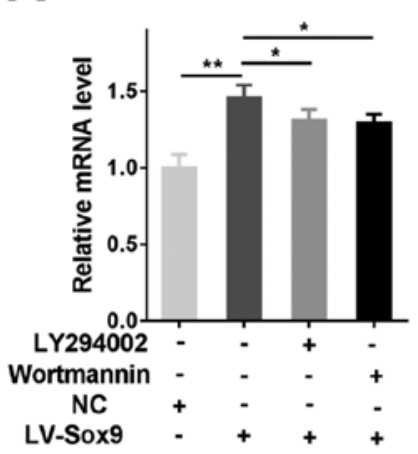

COL1

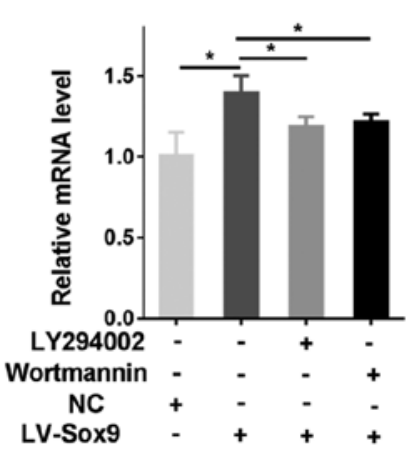

PAI-1

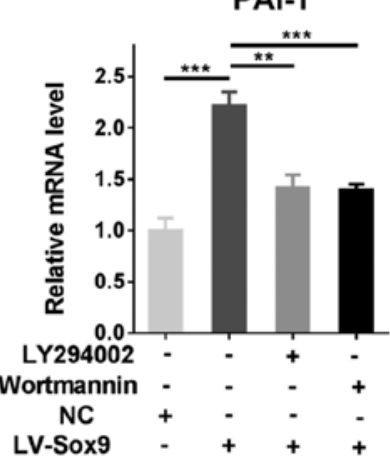

Fibronectin

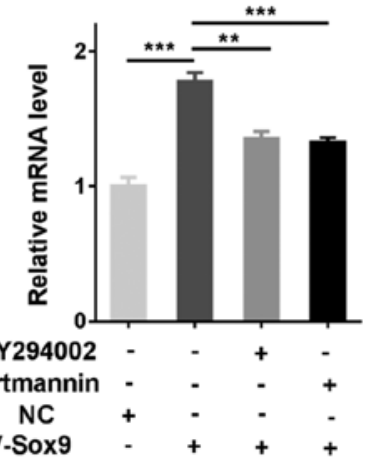

B $\begin{array}{lllll}\text { LY294002 - } & - & + & - \\ \text { Wortmannin - } & - & - & + \\ \text { NC + } & - & - & - \\ \text { LV-Sox9 - } & + & + & +\end{array}$

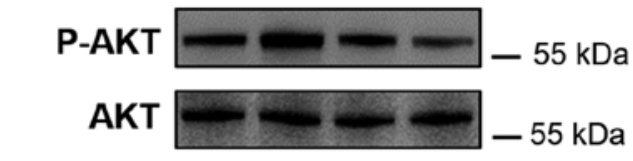

Vimentin $=-55 \mathrm{kDa}$

COL1

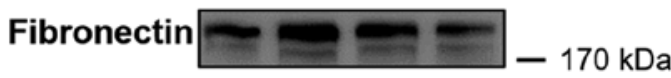

$\beta$-actin $=-40 \mathrm{kDa}$

C
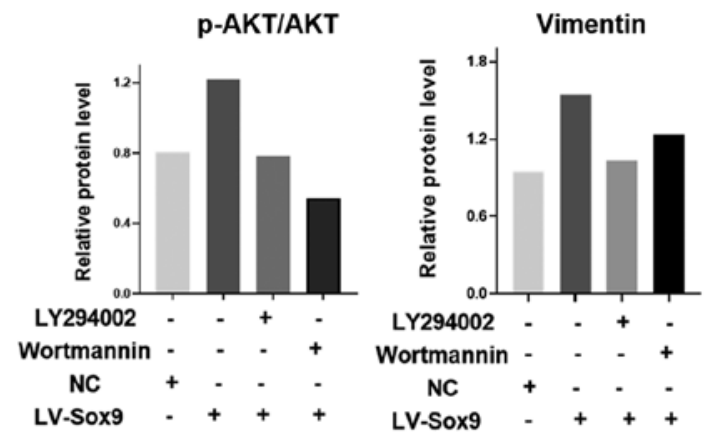

COL1
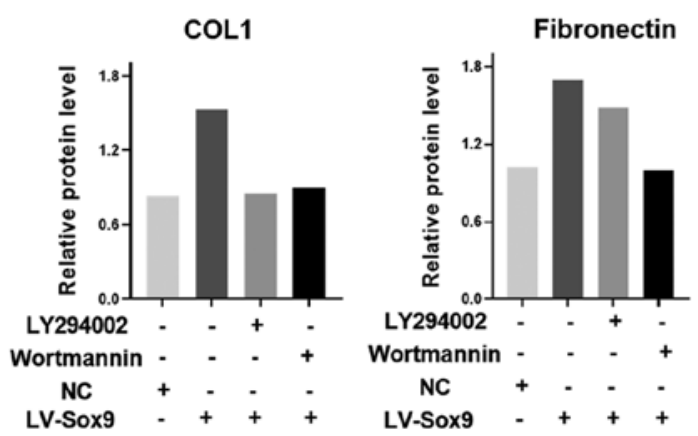

Figure 5. Blockade of PI3K/AKT signaling pathway by PI3K inhibitors alleviates tubular epithelial-mesenchymal transition and extracellular matrix aggregation induced by the overexpression of Sox9 in tubular epithelial cells. NRK-52E cells transfected with LV-Sox9 or NC were treated with $10 \mu \mathrm{M}$ LY29002 or $1 \mu \mathrm{M}$ wortmannin for $48 \mathrm{~h}$. (A) Reverse transcription-quantitative PCR was used to analyze the expression levels of Vimentin, PAI-1, COL1 and fibronectin in LY294002- or wortmannin-treated NRK-52E cells. (B) Western blotting was used to analyze the expression levels of p-AKT, AKT, Vimentin, COL1 and fibronectin in LY294002- or wortmannin-treated NRK-52E cells. (C) Semi-quantification of the expression levels presented in part (B). $n=3 / g r o u p$, western blotting experiments were repeated once. ${ }^{*} \mathrm{P}<0.05,{ }^{* * *} \mathrm{P}<0.01,{ }^{* * * *} \mathrm{P}<0.001$. Data are presented as the mean $\pm \mathrm{SD}$. LV-Sox9, stabilized Sox9 expressing lentivirus; NC, negative control; PAI-1, plasminogen activator inhibitor 1; COL1, collagen 1; p-, phosphorylated.

the mRNA and protein expression levels of Vimentin, PAI-1, COL1, fibronectin and the mRNA expression levels of CTGF, which is consistent with the characteristic features of renal tubular EMT and ECM aggregation under renal fibrosis (7-9). Notably, previous studies have also reported a role for Sox9 in the process of EMT and ECM aggregation; for example, Sox9 
was found expressed in the cardiac cushions, where it promoted EMT processes to form valve structures (43). In addition, Sox9 was identified as a crucial regulator of cardiac fibrosis during ischemic injury $(18,36)$. Furthermore, the genetic disruption of Sox 9 attenuated liver fibrosis by downregulating the expression levels of osteopontin, which is an important component of the ECM and can also promote fibrosis (20). Notably, in the present study, the overexpression of Sox 9 was discovered to potentiate the tubular EMT and ECM aggregation induced by TGF- $\beta 1$. This finding further indicated that Sox 9 may serve a critical role in the processes of EMT and ECM aggregation in tubular epithelial cells, following potential upregulation of phosphorylated Sox 9 expression levels induced by TGF- $\beta 1$. These hypotheses were consistent with a previous study, which reported that TGF- $\beta$ promoted the phosphorylation of Sox 9 protein expression levels in chondrocytes (44).

Numerous previous studies have revealed that Sox 9 primarily acts through the $\mathrm{Wnt} / \beta$-catenin signaling pathway in tumorigenesis and metastasis $(45,46)$. In addition, the sustained activation of this signaling pathway was linked to CKD and renal fibrosis in patients and experimental animal models (47). However, the present study revealed that the changes in the mRNA and protein expression levels of $\beta$-catenin were not statistically different to the NC-transfected cells when Sox9 was overexpressed in renal tubular epithelial cells. Interestingly, it has been suggested that the detection of $\beta$-catenin expression level may not be a sensitive indicator of the Wnt/ $\beta$-catenin signaling pathway activation $(48,49)$. Therefore, additional important molecules involved in the Wnt/ $\beta$-catenin signaling pathway were detected. Unfortunately, no significant differences were observed in the mRNA expression levels of the Wnt receptor, FZD5, and its target genes, c-Myc and TCF4, following the overexpression of Sox 9 in renal tubular epithelial cells, which indicated that Sox9 may not activate the $\mathrm{Wnt} / \beta$-catenin signaling pathway to promote renal tubular EMT and ECM aggregation in renal tubular epithelial cells.

The present study identified that Sox9 was involved in the PI3K/AKT signaling pathway from mRNA transcriptome analysis using RNA-seq technology. In addition, Sox9 upregulated the phosphorylation levels of AKT without affecting the total protein expression levels of AKT. These results are consistent with a previous study, in which the phosphorylation levels of AKT and the PI3K subunit, PI3K catalytic subunit $\alpha$ isoform, were downregulated in chondrocytes following the knockdown of Sox9 (34). Thus, to confirm whether the phosphorylation of AKT mediated renal tubular EMT and ECM aggregation in NRK-52E cells overexpressing Sox9, LY29002 and wortmannin PI3K inhibitors were used; the results revealed that the inhibition of the PI3K/AKT signaling pathway by the inhibitors downregulated expression levels of Vimentin, PAI-1, COL1 and fibronectin in NRK-52E cells overexpressing Sox9. Notably, PI3K inhibitors have been demonstrated to alleviate tubular EMT and renal fibrosis $(50,51)$. These observations indicated that Sox 9 may promote tubular EMT and ECM aggregation in NRK-52E cells through the PI3K/AKT signaling pathway.

Nonetheless, there are several limitations to the present study. First, the study only investigated the effects of Sox9 in one cell line; therefore, further studies should be conducted using other cell lines, such as the NRK-49F cell line, which are rat renal interstitial fibroblasts, to provide more definitive evidence on the role of Sox 9 in renal fibrosis. Secondly, the phosphorylation of AKT was also observed in NC-transfected cells (Fig. 4D). The PI3K inhibitors, LY29002 and wortmannin, may constantly suppress the phosphorylation of AKT, therefore further experiments, such as RNA interference or genetic knockout studies, are required to determine the association between Sox 9 and the PI3K/AKT signaling pathway.

In conclusion, the results of the present study revealed that the expression levels of Sox 9 were upregulated in the renal tubular epithelium following obstructive injury and that the overexpression of Sox 9 may promote tubular EMT and ECM aggregation in vitro through regulating the PI3K/AKT signaling pathway. These findings have implications for the development of novel therapeutic approaches to suppress tubular EMT and ECM aggregation in the kidney.

\section{Acknowledgements}

Not applicable.

\section{Funding}

The present study was supported by the Pediatric Medical Innovation Team of Jiangsu Province (grant. no. CXTDA2017022), the Primary Research \& Development Plan of Jiangsu Province (grant no. BE2017719) and Longgang District Economic and Technology Development Special Fund for Medical and Health Technology Plan Projects of Shenzhen (grant no. LGKCYLWS2018000128).

\section{Availability of data and materials}

All data generated or analyzed during this study are included in this published article.

\section{Authors' contributions}

ZX and CG designed the study and analyzed the data; $\mathrm{ZZ}$ and WW performed the majority of the experiments, analyzed the data and wrote the manuscript; XF and ML helped to perform the animal experiments; XF and HW helped to perform the histological and laboratory analysis; and CG provided constructive suggestions. All authors read and approved the final manuscript.

\section{Ethics approval and consent to participate}

All experiments were approved by the Ethics Committee for the Use of Experimental Animals at Jinling Hospital (Nanjing, China).

\section{Patient consent for publication}

Not applicable.

\section{Competing interests}

The authors declare that they have no competing interests. 


\section{References}

1. Braun L, Sood V, Hogue S, Lieberman B and Copley-Merriman C: High burden and unmet patient needs in chronic kidney disease. Int J Nephrol Renovasc Dis 5: 151-163, 2012.

2. Coresh J, Selvin E, Stevens LA, Manzi J, Kusek JW, Eggers P, Van Lente F and Levey AS: Prevalence of chronic kidney disease in the United States. JAMA 298: 2038-2047, 2007.

3. Hsu CY, Vittinghoff E, Lin F and Shlipak MG: The incidence of end-stage renal disease is increasing faster than the prevalence of chronic renal insufficiency. Ann Intern Med 141: 95-101, 2004.

4. Plantinga LC, Boulware LE, Coresh J, Stevens LA, Miller ER III, Saran R, Messer KL, Levey AS and Powe NR: Patient awareness of chronic kidney disease: Trends and predictors. Arch Intern Med 168: 2268-2275, 2008.

5. Jha V, Garcia-Garcia G, Iseki K, Li Z, Naicker S, Plattner B, Saran R, Wang AY and Yang CW: Chronic kidney disease: Global dimension and perspectives. Lancet 382: 260-272, 2013.

6. Eddy AA: Overview of the cellular and molecular basis of kidney fibrosis. Kidney Int Suppl (2011) 4: 2-8, 2014.

7. Duffield JS: Cellular and molecular mechanisms in kidney fibrosis. J Clin Invest 124: 2299-2306, 2014.

8. Lovisa S, Zeisberg M and Kalluri R: Partial epithelial-to-mesenchymal transition and other new mechanisms of kidney fibrosis. Trends Endocrinol Metab 27: 681-695, 2016.

9. LeBleu VS, Taduri G, O'Connell J, Teng Y, Cooke VG, Woda C, Sugimoto $\mathrm{H}$ and Kalluri R: Origin and function of myofibroblasts in kidney fibrosis. Nat Med 19: 1047-1053, 2013.

10. Nieto MA, Huang RY, Jackson RA and Thiery JP: EMT: 2016 Cell 166: 21-45, 2016.

11. Gordon CT, Tan TY, Benko S, Fitzpatrick D, Lyonnet S and Farlie PG: Long-range regulation at the SOX9 locus in development and disease. J Med Genet 46: 649-656, 2009.

12. Foster JW, Dominguez-Steglich MA, Guioli S, Kwok C, Weller PA, Stevanović M, Weissenbach J, Mansour S, Young ID, Goodfellow PN, et al: Campomelic dysplasia and autosomal sex reversal caused by mutations in an SRY-related gene. Nature 372: 525-530, 1994

13. Wagner T, Wirth J, Meyer J,Zabel B, Held M,Zimmer J, Pasantes J, Bricarelli FD, Keutel J, Hustert E, et al: Autosomal sex reversal and campomelic dysplasia are caused by mutations in and around the SRY-related gene SOX9. Cell 79: 1111-1120, 1994.

14. Haldin CE and LaBonne C: SoxE factors as multifunctional neural crest regulatory factors. Int J Biochem Cell Biol 42: 441-444, 2010

15. Bowen KA, Doan HQ, Zhou BP, Wang Q, Zhou Y, Rychahou PG and Evers BM: PTEN loss induces epithelial-mesenchymal transition in human colon cancer cells. Anticancer Res 29: 4439-4449, 2009.

16. Endo Y, Deonauth K, Prahalad P, Hoxter B, Zhu Y and Byers SW: Role of Sox-9, ER81 and VE-cadherin in retinoic acid-mediated trans-differentiation of breast cancer cells. PLoS One 3: e2714, 2008.

17. Hanley KP, Oakley F, Sugden S, Wilson DI, Mann DA and Hanley NA: Ectopic SOX9 mediates extracellular matrix deposition characteristic of organ fibrosis. J Biol Chem 283: 14063-14071, 2008

18. Lacraz GPA, Junker JP, Gladka MM, Molenaar B, Scholman KT, Vigil-Garcia M, Versteeg D, de Ruiter H, Vermunt MW, Creyghton MP, et al: Tomo-seq identifies SOX9 as a key regulator of cardiac fibrosis during ischemic injury. Circulation 136 1396-1409, 2017

19. Oh CD, Lu Y, Liang S, Mori-Akiyama Y, Chen D, de Crombrugghe B and Yasuda H: SOX9 regulates multiple genes in chondrocytes, including genes encoding ECM proteins, ECM modification enzymes, receptors, and transporters. PLoS One 9: e107577, 2014.

20. Pritchett J, Harvey E, Athwal V, Berry A, Rowe C, Oakley F, Moles A, Mann DA, Bobola N, Sharrocks AD, et al: Osteopontin is a novel downstream target of SOX9 with diagnostic implications for progression of liver fibrosis in humans. Hepatology 56 1108-1116, 2012

21. Arvaniti E, Moulos P, Vakrakou A, Chatziantoniou C, Chadjichristos C, Kavvadas P, Charonis A and Politis PK Whole-transcriptome analysis of UUO mouse model of renal fibrosis reveals new molecular players in kidney diseases. Sci Rep 6: 26235, 2016.

22. Bennett MR, Czech KA, Arend LJ, Witte DP, Devarajan P and Potter SS: Laser capture microdissection-microarray analysis of focal segmental glomerulosclerosis glomeruli. Nephron Exp Nephrol 107: e30-e40, 2007.
23. Sumi E, Iehara N, Akiyama H, Matsubara T, Mima A, Kanamori H, Fukatsu A, Salant DJ, Kita T, Arai H and Doi T: SRY-related HMG box 9 regulates the expression of Col4a2 through transactivating its enhancer element in mesangial cells. Am J Pathol 170: 1854-1864, 2007.

24. Livak KJ and Schmittgen TD: Analysis of relative gene expression data using real-time quantitative PCR and the 2(-Delta Delta C(T)) method. Methods 25: 402-408, 2001

25. Trapnell C, Hendrickson DG, Sauvageau M, Goff L, Rinn JL and Pachter L: Differential analysis of gene regulation at transcript resolution with RNA-seq. Nat Biotechnol 31: 46-53, 2013.

26. Ashburner M, Ball CA, Blake JA, Botstein D, Butler $\mathrm{H}$, Cherry JM, Davis AP, Dolinski K, Dwight SS, Eppig JT, et al: Gene ontology: Tool for the unification of biology. The gene ontology consortium. Nat Genet 25: 25-29, 2000.

27. Kanehisa M, Goto S, Sato Y, Kawashima M, Furumichi M and Tanabe M: Data, information, knowledge and principle: Back to metabolism in KEGG. Nucleic Acids Res 42 (Database Issue): D199-D205, 2014.

28. Chevalier RL, Forbes MS and Thornhill BA: Ureteral obstruction as a model of renal interstitial fibrosis and obstructive nephropathy. Kidney Int 75: 1145-1152, 2009.

29. Santos JC, Carrasco-Garcia E, Garcia-Puga M, Aldaz P, Montes M, Fernandez-Reyes M, de Oliveira CC, Lawrie CH, Araúzo-Bravo MJ, Ribeiro ML and Matheu A: SOX9 elevation acts with canonical WNT signaling to drive gastric cancer progression. Cancer Res 76: 6735-6746, 2016.

30. Kawai T, Yasuchika K, Ishii T, Miyauchi Y, Kojima H, Yamaoka R, Katayama H, Yoshitoshi EY, Ogiso S, Kita S, et al: SOX9 is a novel cancer stem cell marker surrogated by osteopontin in human hepatocellular carcinoma. Sci Rep 6: 30489, 2016.

31. Liu JA, Wu MH, Yan $\mathrm{CH}$, Chau BK, So H, Ng A, Chan A, Cheah KS, Briscoe J and Cheung M: Phosphorylation of Sox9 is required for neural crest delamination and is regulated downstream of BMP and canonical Wnt signaling. Proc Natl Acad Sci USA 110: 2882-2887, 2013.

32. Blache P, van de Wetering M, Duluc I, Domon C, Berta P, Freund JN, Clevers H and Jay P: SOX9 is an intestine crypt transcription factor, is regulated by the Wnt pathway, and represses the CDX2 and MUC2 genes. J Cell Biol 166: 37-47, 2004.

33. Ikegami D, Akiyama H, Suzuki A, Nakamura T, Nakano T, Yoshikawa $\mathrm{H}$ and Tsumaki N: Sox9 sustains chondrocyte survival and hypertrophy in part through Pik3ca-Akt pathways. Development 138: 1507-1519, 2011

34. Zhu Z, Dai J, Liao Y and Wang T: Sox 9 protects against human lung fibroblast cell apoptosis induced by LPS through activation of the AKT/GSK3 $\beta$ pathway. Biochemistry (Mosc) 82: 606-612, 2017.

35. Chaboissier MC, Kobayashi A, Vidal VI, Lützkendorf S, van de Kant HJ, Wegner M, de Rooij DG, Behringer RR and Schedl A: Functional analysis of Sox8 and Sox9 during sex determination in the mouse. Development 131: 1891-1901, 2004.

36. Stolt CC, Lommes P, Sock E, Chaboissier MC, Schedl A and Wegner M: The Sox 9 transcription factor determines glial fate choice in the developing spinal cord. Genes Dev 17: 1677-1689, 2003.

37. Geng F, Zhu W, Anderson RA, Leber B and Andrews DW: Multiple post-translational modifications regulate E-cadherin transport during apoptosis. J Cell Sci 125: 2615-2625, 2012.

38. Kumar S, Liu J, Pang P, Krautzberger AM, Reginensi A, Akiyama H, Schedl A, Humphreys BD and McMahon AP: Sox9 activation highlights a cellular pathway of renal repair in the acutely injured mammalian kidney. Cell Rep 12: 1325-1338, 2015.

39. Liu J, Kumar S, Dolzhenko E, Alvarado GF, Guo J, Lu C, Chen Y, Li M, Dessing MC, Parvez RK, et al: Molecular characterization of the transition from acute to chronic kidney injury following ischemia/reperfusion. JCI Insight 2: e94716, 2017.

40. Liu BC, Tang TT, Lv LL and Lan HY: Renal tubule injury: A driving force toward chronic kidney disease. Kidney Int 93: 568-579, 2018 .

41. Schiessl IM: The role of tubule-interstitial crosstalk in renal injury and recovery. Semin Nephrol 40: 216-231, 2020.

42. Tan RJ, Zhou D and Liu Y: Signaling crosstalk between tubular epithelial cells and interstitial fibroblasts after kidney injury. Kidney Dis (Basel) 2: 136-144, 2016

43. Garside VC, Cullum R, Alder O, Lu DY, Vander Werff R, Bilenky M, Zhao Y, Jones SJ, Marra MA, Underhill TM and Hoodless PA: SOX9 modulates the expression of key transcription factors required for heart valve development. Development 142: 4340-4350, 2015 . 
44. Coricor G and Serra R: TGF- $\beta$ regulates phosphorylation and stabilization of Sox 9 protein in chondrocytes through p38 and Smad dependent mechanisms. Sci Rep 6: 38616, 2016.

45. Wang H, He L, Ma F, Regan MM, Balk SP, Richardson AL and Yuan X: SOX9 regulates low density lipoprotein receptor-related protein 6 (LRP6) and T-cell factor 4 (TCF4) expression and Wnt $/ \beta$-catenin activation in breast cancer. J Biol Chem 288: 6478-6487, 2013.

46. Ma F, Ye H, He HH, Gerrin SJ, Chen S, Tanenbaum BA, Cai C, Sowalsky AG, He L, Wang H, et al: SOX9 drives WNT pathway activation in prostate cancer. J Clin Invest 126: 1745-1758, 2016.

47. Wang Y, Zhou CJ and Liu Y: Wnt signaling in kidney development and disease. Prog Mol Biol Transl Sci 153: 181-207, 2018

48. Zong Y, Huang J, Sankarasharma D, Morikawa T, Fukayama M, Epstein JI, Chada KK and Witte ON: Stromal epigenetic dysregulation is sufficient to initiate mouse prostate cancer via paracrine Wnt signaling. Proc Natl Acad Sci USA 109: E3395-E3404, 2012.
49. Placencio VR, Sharif-Afshar AR, Li X, Huang H, Uwamariya C, Neilson EG, Shen MM, Matusik RJ, Hayward SW and Bhow mick NA: Stromal transforming growth factor-beta signaling mediates prostatic response to androgen ablation by paracrine Wnt activity. Cancer Res 68: 4709-4718, 2008.

50. Du R, Xia L, Ning X, Liu L, Sun W, Huang C, Wang H and Sun S: Hypoxia-induced Bmil promotes renal tubular epithelial cell-mesenchymal transition and renal fibrosis via PI3K/Akt signal. Mol Biol Cell 25: 2650-2659, 2014.

51. Zeng R, Yao Y, Han M, Zhao X, Liu XC, Wei J, Luo Y, Zhang J, Zhou J, Wang S, et al: Biliverdin reductase mediates hypoxia-induced EMT via PI3-kinase and Akt. J Am Soc Nephrol 19: 380-387, 2008. 